$10-23-2015$

\title{
Clinical Supervision in Allied Health in Australia: A Model of Allied Health Clinical Supervision Based On Practitioner Experience
}

Sue Fitzpatrick

Charles Sturt University, sue.fitzpatrick@hotmail.com

Megan Smith

Charles Sturt University, mesmith@csu.edu.au

Clare Wilding

Charles Sturt University, cwilding@knowledgemoves.com.au

Follow this and additional works at: https://nsuworks.nova.edu/ijahsp

Part of the Medicine and Health Sciences Commons

\section{Recommended Citation}

Fitzpatrick S, Smith M, Wilding C. Clinical Supervision in Allied Health in Australia: A Model of Allied Health Clinical Supervision Based On Practitioner Experience. The Internet Journal of Allied Health Sciences and Practice. 2015 Oct 23;13(4), Article 13.

This Manuscript is brought to you for free and open access by the College of Health Care Sciences at NSUWorks. It has been accepted for inclusion in Internet Journal of Allied Health Sciences and Practice by an authorized editor of NSUWorks. For more information, please contact nsuworks@nova.edu. 


\title{
Clinical Supervision in Allied Health in Australia: A Model of Allied Health Clinical Supervision Based On Practitioner Experience
}

\begin{abstract}
Purpose: The purpose of this manuscript is to identify key elements of allied health clinical supervision based on allied health practitioner's experiences. Method: This study was conducted with qualitative methodology, including content analysis, and draws on hermeneutic interpretation of texts. Data were collected through an online survey in an Australian health service and subsequent focus groups. Results: Findings revealed four key dimensions including accessibility of regular clinical supervision, relationships between the supervisor and supervisee, clarity about the purpose, and roles and a focus on meeting the supervisee's needs; these dimensions were central to the allied health practitioner's experience of successful clinical supervision. A model of clinical supervision is proposed that is based on these four identified key dimensions. This model could be used as a broad schema to achieve a successful clinical supervision experience in allied health. Conclusion: This study contributes to the growing body of clinical supervision research by specifically addressing allied health needs in clinical supervision and proposing a model for its implementation. The authors contribute to the discussion about clinical supervision and its implementation by addressing needs that relate specifically to allied health and by developing a deeper understanding of the clinical supervision experiences of allied health clinicians. This new understanding provides a foundation for clinician-focused supervision, policy development and implementation.
\end{abstract}

\section{Author Bio(s)}

- Sue Fitzpatrick, BAppSc(SP), is a doctoral student in the School of Community Health at Charles Sturt University in Australia.

- Megan Smith, BAppSc(PT), MAppSc(PT), PhD, is Head of School and Associate Professor at Charles Sturt University in the School of Community Health.

- Clare Wilding, BAppSc(OT), MAppSc(OT), PhD, is an Adjunct Senior Lecturer in the School of Community Health at Charles Sturt University. 


\title{
TIJAHSP \\ The Internet Joưnal of Allied Health Sciences and Practice \\ Dedicated to allied health professional practice and education \\ Vol. 13 No. 4 ISSN 1540-580X \\ Clinical Supervision in Allied Health in Australia: A Model of Allied Health Clinical Supervision Based On Practitioner Experience
}

\author{
Sue Fitzpatrick, BAppSc(SP) ${ }^{1}$ \\ Megan Smith, BAppSc(PT), MAppSc(PT), PhD2 \\ Clare Wilding, BAppSc(OT), MAppSc(OT), $\mathrm{PhD}^{3}$ \\ 1. Charles Sturt University, Doctoral Student \\ 2. Charles Sturt University, Associate Professor, Head of School \\ 3. Charles Sturt University, Adjunct Senior Lecturer
}

Australia

\begin{abstract}
Purpose: The purpose of this manuscript is to identify key elements of allied health clinical supervision based on allied health practitioner's experiences. Method: This study was conducted with qualitative methodology, including content analysis, and draws on hermeneutic interpretation of texts. Data were collected through an online survey in an Australian health service and subsequent focus groups. Results: Findings revealed four key dimensions including accessibility of regular clinical supervision, relationships between the supervisor and supervisee, clarity about the purpose, and roles and a focus on meeting the supervisee's needs; these dimensions were central to the allied health practitioner's experience of successful clinical supervision. A model of clinical supervision is proposed that is based on these four identified key dimensions. This model could be used as a broad schema to achieve a successful clinical supervision experience in allied health. Conclusion: This study contributes to the growing body of clinical supervision research by specifically addressing allied health needs in clinical supervision and proposing a model for its implementation. The authors contribute to the discussion about clinical supervision and its implementation by addressing needs that relate specifically to allied health and by developing a deeper understanding of the clinical supervision experiences of allied health clinicians. This new understanding provides a foundation for clinician-focused supervision, policy development and implementation.
\end{abstract}

\section{INTRODUCTION}

The purpose of this manuscript is to identify factors that make clinical supervision successful from the point of view of allied health staff. The study described in this paper was part of a wider study of allied health clinical supervision which aimed to develop a guide for supervision policy development. Successful clinical supervision is defined for the purpose of this paper as the creation of conditions in the workplace that enable reflection on clinical practice, facilitate teaching and learning and provide a safeguard or protection for clients. ${ }^{1}$ Published examples of research which has investigated clinical supervision in allied health include studies of the experiences, understanding, and relevance of clinical supervision in dietetics by Paulin in 2010, and in 2009, Hall and Cox examined the term "clinical supervision" and its appropriateness for physiotherapy.2,3 Similarly, professionbased papers appear for speech pathology, social work, and occupational therapy.4-7 When clinical supervision for allied health has been the main focus, the inclusion criteria are often widened to include nursing, due to difficulty recruiting sufficient allied health personnel to participate. ${ }^{8}$ Missing in the literature are studies involving only allied health professionals in clinical supervision, and studies examining in-depth their particular experiences. The study of allied health specific clinical supervision will clarify the existence of allied health specific needs in clinical supervision. A study with a specific focus on clinical supervision in allied health would reveal unique issues, requisites, and actions that are particular to allied health, the outcome of which is a more universal approach to allied health clinical supervision. 
Previous studies of clinical supervision have identified four key dimensions: the presence of a successful supervisory relationship, accessible clinical supervision, clarity of expectations in clinical supervision, and supervision that focuses on meeting the needs of the supervisee, as important issues in clinical supervision in allied health, nursing and medicine (Table 1). These four dimensions have been described either together or in isolation; however, no integrated model of clinical supervision has emerged. The result is an incomplete understanding of the needs of staff supervising, or being supervised, in allied health that would adequately inform policy development. In a previous publication, the authors have published a review of the literature that summarized the existing supervision literature as lacking a clear understanding of what clinical supervision means to allied health and how it should be implemented. ${ }^{1}$

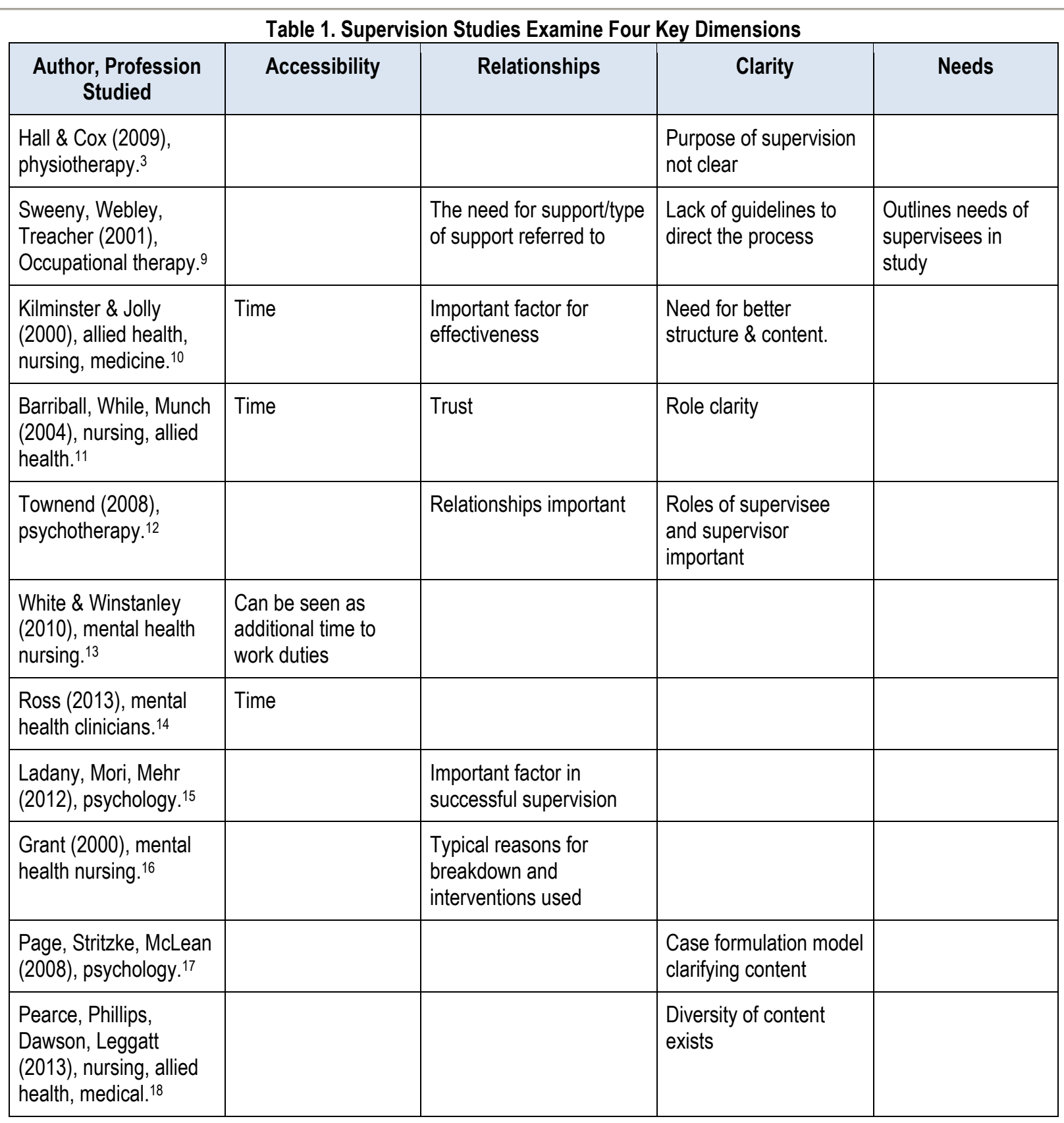

Therefore the aims of this study were to:

1. Develop an understanding of the clinical supervision experiences of allied health clinicians, and

2. Provide a foundation on which to base clinician-focused supervision implementation and policy development. 


\section{METHODS}

A qualitative research approach was used to explore and understand allied health clinicians' experiences in clinical contexts. A qualitative approach uses open concepts rather than predetermined definitions, inferential understanding rather than measurement, an interpretive perspective for analysis of text, and detailed verbal descriptions rather than numerical representations. ${ }^{19} \mathrm{~A}$ qualitative approach allows for multiple perspectives and the ability to complete in-depth investigation, which in this instance, was detailed exploration of the experiences of clinical supervision. ${ }^{20}$ From the range of qualitative research approaches, this study drew on the methods and philosophies of hermeneutics. The nature of hermeneutics is to interpret, or make meaning of an experience that is shared with participants. ${ }^{21,22}$ The participants' descriptions of the experience under investigation are collected as texts, and these texts are interpreted by the researcher to develop an in-depth understanding of the experience. The recognition of the history and views of the researcher are paramount in arriving at a new understanding of the experience being studied. Gadamer and Linge ${ }^{23}$ described this as "fusion of horizons," whereby there is a joining of the meaning of the text and of the understanding of the researcher to reveal a new understanding. ${ }^{23}$ The principal researcher in this study was an allied health head of department, working within the health service. The role of the researcher in this study was both as text collector and interpreter. This was acknowledged throughout the study to minimize the effect that the researcher's position would have on participants.

\section{Ethics}

Approval from Charles Sturt University Australia and Wollongong University Australia Research and Ethics Councils was sought and granted. Participants were reassured of their anonymity and were given opportunity for anonymous replies or feedback.

\section{Participants}

Purposive sampling was used in this study to achieve the specific aims of the research, which in this study was allied health staff who had experienced clinical supervision. ${ }^{24}$ All allied health clinicians, as defined by the New South Wales Health Service Health Professionals (State) Award (2007), who had experienced supervision, either as a supervisor or supervisee, and were current employees of the specified health service that was the location for the research were invited to participate. ${ }^{25}$ For the purpose of the study, the term supervisee was defined as any allied health practitioner who had received supervision in either a one-to-one or group situation and by a peer/peers or from a manager or more senior staff member. A supervisor was defined as any allied health practitioner who had provided any supervisory activities. These criteria applied to both present and past roles, and participants were able to identify themselves as either one or both roles. Both supervisors and supervisees were recruited so that supervision could be explored from both sides of the supervision dyad. Supervisors and supervisees who had a range of supervisory experience were invited to participate to include a range of experiences along the supervisory spectrum. Recruitment was by invitation via health service email that enabled the maximum number of staff to be contacted. Participants volunteered from a range of professions within allied health.

The participating health service in this study was one of eight within New South Wales, Australia, and encompassed metropolitan, outer metropolitan, regional, and rural locations. This site was chosen because it was anticipated that the results may have broad relevance to other Australian health services as the research crossed all geographical locations and health environs. The inclusion of only one area health service allowed for timely completion of the study, as the logistics of seeking consistent allied health representation within one area health service was more easily coordinated than using multiple services.

The views and history of the principal researcher are important for the methodology utilised in this study. The principal researcher was a doctoral student and a current head of an allied health department and performed the role of survey distributer, overseer of the research process, and data interpreter. The views of the principal researcher about clinical supervision were founded on extensive reading of the literature across multiple professions. The principal researcher believed that clinical supervision issues and policy could cross professional boundaries; however, she was open to any and all experiences and requirements in clinical supervision for allied health.

\section{Text Construction}

The term "text" can apply to the written word (including documents), conversations (including transcriptions), drawings, and transcripts. ${ }^{21}$ In this study, texts were generated from a survey that required in-depth written response to participants' experiences of supervision. Participants also participated in action research group discussions. The action research groups were used to build on the survey findings in order to explain phenomena identified in the survey. It also contributed to data triangulation by using different methods to collect the data. This manuscript only reports on information and texts resulting from the survey. Further findings from the action research groups are to be published in a future paper by the authors.

(c) The Internet Journal of Allied Health Sciences and Practice, 2015 


\section{Survey}

Invitations were sent to the allied health population via an institutional email to participate in an online survey of their supervisory experiences. The anonymous survey was hosted by an external survey product, and as such, neither identified the participant individually nor health profession of the participant. Thus, the anonymity of participants was protected, as re-identification may have been possible given the researcher was employed with the health service.

There were a total of seven questions (Table 2). Two questions asked closed questions: participants were asked to state how many years of experience they had as health professionals and whether they had more experience as a supervisee or supervisor. Five other questions were more open-ended. One of these short open-ended questions asked participants to state what he or she considered to be the three most important factors to the process of supervision. Another question asked participants to provide a description of an experience with clinical supervision with enough detail that the situation, issues, and outcomes could be easily understood.

Table 2. Survey Questions.

\begin{tabular}{|l|l|}
\hline 1 & How many years have you worked in your professional field? \\
\hline 2 & $\begin{array}{l}\text { Do you consider you have more experience as a supervisor (one who supervises) or supervisee (one who is } \\
\text { supervised)? }\end{array}$ \\
\hline 3 & $\begin{array}{l}\text { Please provide a short description of an experience you have had with clinical supervision. Your story should contain } \\
\text { enough detail so that we can understand the situation and any issues. Describe the actions of those involved and } \\
\text { explain what the outcome was. }\end{array}$ \\
\hline 4 & Are you aware of any problems that exist in your area in relation to clinical supervision? \\
\hline 5 & How do you think policy on supervision would affect your experience of supervision? \\
\hline 6 & What 3 factors do you consider most important to the process of supervision? \\
\hline 7 & Do you think it would be helpful to have a whole of allied health approach to clinical supervision? \\
\hline
\end{tabular}

\section{Text Interpretation}

Philosophical hermeneutics was applied to this research using tools which included questions asked of the text and emerging from the text and the use of the hermeneutic circle. This text interpretation approach using hermeneutics encourages understanding that acknowledges pre-understandings, ideas, categories or theories the researcher brings to the interpretation and allows these conceptualizations to be integral to the horizon of the text itself. It is important to understand that this knowledge forms part of the interpretation of text within this study and is also an important part of the hermeneutic. The principal researcher immersed herself in the text and identified categories. ${ }^{26}$ From the categories, themes emerged that allowed interpretation of the text to a deeper level of abstraction. Van Manen described themes as a "simplification and a way of "capturing the phenomenon one tries to understand."27

The texts were read multiple times by the principal researcher to ensure an overall sense of the whole key words from each response were underlined and these words used as initial codes or themes. ${ }^{29}$ Similar themes were then grouped into higher order headings or categories to reduce the number of categories. Elo and Kyngäs described this process as "abstraction." ${ }^{30}$ This process of moving from the "part" of single words to the "whole" of sentences form the hermeneutic circle. ${ }^{31}$

In one example, both accessibility and regularity, when described as being absent, were deemed to be threats or barriers to clinical supervision. The main category themes were presented to the groups with sample stories from the survey text and served as a scaffold for identifying essential inclusions for developing key principles for clinical supervision.

Following repeated engagement with the text, exemplar descriptions were constructed to illustrate archetypal in-depth and contextualized understandings of the participants' experiences. These case stories were a combination of different participants' experiences that exemplified the study's themes. Elo and Kyngäs considered that constant engagement and checking and rechecking of themes helps to ensure that saturation of the text occurs. ${ }^{30}$ The repeating engagement with the text as an attempt to make sense of pieces of the text in the context of the meaning of the whole text was another example of the hermeneutic circle. ${ }^{31}$

(c) The Internet Journal of Allied Health Sciences and Practice, 2015 
This repeating dialogue with, and analysis of, the text was followed by critique, reiteration, and reanalysis. ${ }^{29}$ This process was consistent with a hermeneutic dialectic; that is, one that continually reconsiders a position or construction with a new construction or understanding. ${ }^{28}$ The hermeneutic process was thus dialogically a combination of the horizon of the researcher and the supervision experiences being studied which resulted in a coalesced understanding or horizon. ${ }^{32}$ This is the concept of a fusion of horizons or the formation of a new shared understanding of the experience being studied. 23

Questions asked of the text during analysis included: What is the overall experience of supervision: is it positive or negative? What is the participant doing and feeling? What is main message the participant is trying to convey? When identified categories did not fit with the main themes identified, or were applicable across more than one theme, further analysis was required of each story to describe the essence or core message from each description. Themes were established and re-established in an attempt to encompass all of the issues identified by the participants.

\section{Quality of the Research Process}

Creswell addresses quality criteria including credibility, or how accurate the findings represent the participant's experience, auditability or the details of the steps in text analysis, and interpretation and fittingness or an ability for the reader to understand the process and findings and decide on its relevance to them and their practice. The following procedures, described by Creswell, were employed in this study to ensure the credibility of the findings. ${ }^{33}$ Triangulation was employed by collecting multiple text sources from the same population of allied health professionals. This was achieved by extracting themes from the survey with the understanding of the content from the focus groups, allowing the researcher to ensure the emerging themes were representative of the wider population. Prolonged engagement was the second procedure and was achieved through the primary researcher engaging with the text intensively over a 3-4 month period and then over 2 years using the written text as well as engaging with auditory recordings of focus group text. The third procedure was member checking. The action research groups were used to check the relevance and accuracy of the text from the survey; this ensured that the participants played an active role in shaping and refining the findings. The action research groups confirmed the accuracy of the survey text through their strong identification with the stories written by the survey participants. In the fourth instance, audit trails of the content analysis of the text from the survey illustrated the movement from text to themes; this ensures the findings and conclusions re supported by the text. ${ }^{33}$ Finally, a thick rich description permits an evaluation of the transferability of results. This can occur though a detailed description of the study setting or context and allows the reader to decide whether the study results transfer to other settings. ${ }^{33}$ Text saturation was achieved when the themes emerging across all survey text showed a strong consistency of ideas with minimal variability and where all text fitted well into the identified themes. This suggested to the researcher that no further text was needed and the text was considered to be at saturation.

\section{RESULTS}

The survey was completed by 113 of approximately 1350 allied health staff members. Thus a response rate of $8 \%$, which may have been low due to some employees not having access to the internet within the workplace. Participants varied in their years of clinical experience (see Table 2) and in types of experience in clinical supervision (see Table 3).

Table 2. Years of clinical experience.

\begin{tabular}{|l|l|}
\hline Years of Clinical Experience & \multicolumn{1}{|c|}{ \% of Respondents } \\
\hline $1-2$ & 10.6 \\
\hline $2-4$ & 15.0 \\
\hline $5-9$ & 24.8 \\
\hline $10+$ & 49.6 \\
\hline
\end{tabular}


Table 3. Supervision Experience

\begin{tabular}{|l|c|}
\hline Supervision Experience & \% of Respondents \\
\hline Supervisor & 37.2 \\
\hline Supervisee & 41.6 \\
\hline Both equally & 21.2 \\
\hline
\end{tabular}

Four main categories or themes emerged from the participants' experiences as playing a significant role in clinical supervision.

\section{Lack of access to consistent clinical supervision}

Participants experienced access to clinical supervision as inconsistent. For example, participant 64 described difficulty accessing clinical supervision: "Since entering [the health service], I have not received professional clinical supervision...I believe that this is greatly needed and should be addressed." Consistency and availability of supervision were also problems for participant 47: "Supervision for me on the whole 9 years has been ad hoc even though there was a departmental policy. More often than not supervision was cancelled".

Many of the participants expressed the desire to receive clinical supervision as a feature of their everyday practice regardless of their years of experience, geographical location, or part-time status. Participant 65 explained that being both part-time and geographically separated from other campuses of the health service affected her access to supervision: "Difficulties with access geographically and timing as both of us were part-time".

Some participants reported not receiving any clinical supervision. This absence featured in participant 35's experience: "As a new graduate I had no formal supervision. I had some informal peer supervision from a colleague...there were many times as a new graduate where I was left to cover the hospital on my own with no support, even with as little as one-two months experience as an adult acute therapist."

Participants described feeling lost or abandoned when supervision was absent or failed to meet their needs. Participant 82 reported having "NO supervision [original emphasis]" and that on her "first day on a job... [I was] left for 4 hours to treat 10 very sick babies," communicating distress by this lack of support.

Availability of time for supervision affected participants' access to supervision. Participants described the experience of difficulty putting aside their clients in order to make time to attend supervision, and supervisors also appeared to struggle to make the time to be regularly available for supervision. "I have frequently found supervision hard to coordinate due to other pressing work issues" (participant 16).

\section{The supervisory relationship is critical}

Relationships appeared to have a key influence on the experience of supervision. For participant 95, described success in supervision when her supervisor changed. "I] got placed with a supervisor whom I didn't interact with as effectively as other members of the department. I requested a change of supervisor...I felt I could communicate issues and cases more comfortably and get much more out of clinical supervision [with the new supervisor]." For stories in which clear negative or positive experiences were described, the success or failure of the key supervisory relationship was revealed to be at the core of these evaluations of these experiences.

The concept of relationship is important within the context of group supervision as well as one to one supervision. Participant 18 described how an experience of poor interpersonal interactions could be a hindrance to successful clinical supervision. Speaking about group supervision, she wrote "Dynamics and personality clashes were the issue....it's important...to feel secure with the person/people involved." Participants considered that it was essential to feel safe during the supervision session: "The most important aspect for me was trust and confidence in supervisor" (participant 100). Participant 58 described how the supervisory relationship broke down irreparably when she felt that her trust in her supervisor was violated: "When supervised, private

(C) The Internet Journal of Allied Health Sciences and Practice, 2015 
information was disclosed to another person without my permission, as a result all trust was lost in the supervisor and I requested that a new supervisor be appointed".

\section{Need for a shared understanding of clinical supervision}

Participants had difficulty predicting what to expect form clinical supervision. There was a lack of shared, clear, and consistent understandings of what clinical supervision would include and how it should be structured. Subsequently, each person in the supervision relationship had different expectations about the purpose, process, and practice of supervision. There was clarity about who participated in clinical supervision, which largely included traditional dyads of a senior person partnered with a junior person. In some supervisory relationships, peers supervised each other and others occurred in groups. There was less clarity about what should happen in clinical supervision and how this should be actioned. Participants who experienced poor supervision recommended that clearer standards and guidelines for supervision were needed, and conversely, participants who had successful experiences of supervision attributed success to having well-developed supervision standards and guidelines.

Descriptions of what was included in or requested from clinical supervision focused either on clinical work and the needs of the client, or support and the need of the clinician. Participant 40's story typified that a focus on clinical work was part of clinical supervision: "I saw my clinical supervisor who advised me how to correctly document the sessions and phone calls with the parent and preschool teacher in case it ever came up in court." The approach to clinical focus in supervision varied and included case discussion, demonstrating specific techniques, sharing and discussing resources, and assessment of clinical competency. Participant 113 described being grateful for support provided in clinical supervision "The main outcome from this was that I was provided with support and had a sounding board to voice my frustration at the situation."

Management of a clinician's performance within the context of supervision was also described; some participants had a positive learning experience and thus acceptance of performance management when included within supervision. "I learnt that performance management is a large component of supervising staff" (participant 60). However, Participant 92 perceived that including performance management as part of supervision distorted and damaged the supervisory relationship. "As a supervisor, I was asked to address some issues with a clinician I was supervising. These issues were related to administrative tasks, yet my role... was for clinical supervision. My manager had delegated the other duties to me to address as she had a poor working relationship with the clinician and acknowledged she wanted to avoid any further negative interaction. Thus I felt that clinical supervision had crossed the line into performance management, and I see them to be two very different things. Supervision was supposed to have been a confidential and 'safe' time for the clinician to discuss any issues with their clinical work. By introducing the performance management component, our supervision relationship was damaged, and the clinician stopped raising issues she was concerned about. I was seen as 'management' rather than as a 'clinical supervisor."

How supervision occurred varied considerably. The level of formality included highly formally structured, regular, one-to-one supervision sessions and informal opportunities to have a discussion with a peer over coffee. Participant 47 experienced less formalized supervision: "What we call 'on the run' supervision has developed as a great way to get supervision from colleagues willing to listen over a cup of coffee." In contrast, participant 54 experienced that "it was helpful having a guideline which outlined points for discussion and areas of performance."

The presence of a predictable or facilitating structure was described as a positive aspect of supervision. Structure was considered to be especially helpful when it clarified the expectations for the supervisee: "It was helpful to have a guideline which outlined points for discussion and areas of performance" (participant 54). The absence of structure conversely created negative effects on the outcomes of supervision. For example, participant 57 stated, "My experience with my supervisor of choice, however, has not been very structured and sometimes I don't know where I am going." Participant 57 indicated a need for clearer goals to be part of her supervision experience. Participant 78 also highlighted the negative impact that a lack of structure can have on the outcome of the supervision session: "[There was] no formal structure or content for the mentoring program [therefore]...mentoring sessions were often less productive." The participants request for a clear structure, clear understanding and agreement about the expectations of the session, as well as the outcome for clinical supervision was evident in the descriptions.

\section{Supervisee needs should drive supervision}

The supervisees' needs within clinical supervision were most frequently described as reflection, support, confidence, and learning. The degree to which each need was included in the clinical supervision experiences predicted a positive or negative

(C) The Internet Journal of Allied Health Sciences and Practice, 2015 
experience. Supervision in which all needs were addressed was experienced more positively than those in which only one or sometimes no needs were considered.

Supervisees appreciated the opportunity for reflection during supervision; they valued the opportunity to think critically about clinical work. Participant 17 wrote: "I enjoy reassurance that I am making the right clinical and service delivery decisions... refreshing my knowledge about policies and procedures with difficult cases. I wish my supervisor would help me to think critically and acknowledge my opinion, rather than give me their opinion first." Supervisors also valued the opportunity that supervision provided to engage in reflection: "As a supervisor I have found clinical supervision rewarding and aids critical thinking" (participant 77).

Support, in the form of being fully present and giving assistance and encouragement, was frequent in descriptions of successful supervision. "My supervisor was very supportive though and helped me through it all" (participant 54). "My first job involved terrific supervision...it was a supportive, nurturing environment that enabled me to build my confidence and skill level" (participant 75). Conversely, for participant 2, absence of support resulted in a dissatisfying supervision experience that left participant 2 feeling disappointed. "Through the course of discussing a case, [I] became emotionally upset, to the point where I was crying. I felt that my supervisor at this time felt that it was inappropriate in supervision, and on reflection, feel that she did not have the capacity to cope with managing the emotional issues that can sometimes come up throughout works as well as she was able to provide practical and/or theoretical guidance."

Developing self-confidence in one's own skills and abilities was regarded as an important goal for supervision. Lack of attention to developing confidence may result in negative experiences of supervision. "I observed a situation recently, where a supervisor did not discuss clinical and professional issues with the supervisee immediately as they developed...The staff member therefore had a very negative experience in their rotation and their confidence was low afterwards" (participant 60).

Learning was considered by the participants to be essential in supervision. Participant 1 described supervision as assisting in the acquisition of new skills and knowledge, as well as providing an opportunity to reflect: "I...have grown tremendously as a clinician. I feel that a large part of this is to do with my experience with supervision...challenging me to think in new ways... [it has been] a helpful way to extend my skills." Participant 94's experience echoed that of Participant 1: "We discussed clinical issues specific to my clinical area. This helped me reflect on my practice and develop goals to improve both my knowledge and skills in oncology." Participant 79 experienced clinical supervision that did not meet her learning needs and was therefore dissatisfying: "I...did not feel I gained insight or knowledge from the supervision."

In summary, the four key themes illustrate the issues that were experienced as being essential to a successful experience for the supervisee. Supervision was considered successful when supervisee needs directed the supervision process and content, when there was easy access to consistent supervision, a good working relationship existed, and clear expectations and understanding between supervisor and supervisee. These findings have been used to assist in the development of a model for clinical supervision for allied health.

\section{DISCUSSION}

This study contributed to a deeper understanding of the clinical supervision experiences of allied health clinicians by providing the perspectives of supervisors and supervisees. The most important finding includes the development of a model of clinical supervision on which to base clinician-focused supervision implementation and policy development.

Based on the above main findings and new understanding that emerged from the survey text, The Allied Health Key Dimensions Model was developed (see model in Figure1). In this model, the needs of the supervisee have been placed at the core of providing clinical supervision. The supervisee has been placed at the center of the model as the text revealed that the needs of the supervisee being met or not met predicted a positive or negative outcome for clinical supervision. When the supervisee is at the center of the supervision process, supervision is viewed within the context of the supervisee. This context drives a shared understanding of the content and process of supervision and subsequently the establishment of a successful relationship and supervision that is regularly accessible. In the public health context, having a shared understanding about what supervision is and how it can meet the supervisee's needs precedes the supervisory relationship in a practical as well as a theoretical sense. The text also illustrated that supervisee needs differ from person to person and clinical context to clinical context, which strengthens the need to clarify expectations of clinical supervision. A model which has the supervisees at the center allows the flexibility to use the model for all clinicians and clinical contexts. ${ }^{34,35}$

The three remaining dimensions build upon the solid foundation of the supervisees needs. Clarity has been positioned next, as

(C) The Internet Journal of Allied Health Sciences and Practice, 2015 
the need for a shared understanding about what happens in clinical supervision is clearly conveyed in the text. The many ways in which supervision can be misguided has been made explicit by participants. Supervisory relationships are positioned next; as the text suggests, a poor relationship can be a hindrance to successful clinical supervision, even where there is a shared understanding of how it should function. Accessibility has been placed in the surrounding circle, as the text strongly indicated that gaining consistent access to supervision was a barrier to the overall success of clinical supervision and must be addressed, as it would be problematic for all other dimensions to be in place if supervisees were unable to access clinical supervision consistently. It is proposed that when all dimensions are addressed, successful supervision is predicted. The model implies that providing effective supervision is not just about the people but about the governance and ability to have the needs of the supervisee met. To apply the model, each dimension ought to be considered in turn, starting from the needs of the supervisee and moving through the dimensions of clarity, relationships and accessibility.

At an organizational level, the model could be used to help establish a clinical supervision policy or procedure and implementation of clinical supervision. Based on the findings of the study, accessibility could be considered by assessing organizational support for time available for supervision. Supervisory relationships could be examined for adequate choice and availability of supervisors. The availability of organizational policy or guidelines could clarify the purpose and process of clinical supervision, and taking action to ensure the organization is familiar with the needs of the supervisee in terms of reflection, support, confidence, and learning and could support meeting those needs.

At a departmental level, the model could be used to firstly introduce the concept of clinical supervision as being superviseecentered and about meeting their needs. The department leader would then arrange adequate training on the content of the organizational policy and expectations for clinical supervision. The department or professional group would ensure access to a range of clinical supervisors to optimize opportunities for positive supervisory relationships, and make arrangements around time and clinical caseload for consistent access to clinical supervision.

To use the model individually, each dimension should again be considered in turn. For example, starting from supervisee needs and moving outward: A discussion to attain clarity about the supervision would occur and include agreement about the standards, the expectations, and what topics and roles should be included and excluded. Next, the supervisor and supervisee would negotiate the boundaries and roles of the supervision including a discussion about who to involve, what should be discussed, and how the supervision should be implemented. A supervisory relationship would then begin, and a subsequent discussion would occur about the frequency of supervision and which times were most suitable for supervision.

It is the opinion of the authors that The Allied Health Key Dimensions Model can be used to evaluate and develop clinical supervision at an organizational, departmental, or individual level. The model provides a visual reminder about all the dimensions that ought to be considered when establishing and evaluating supervision, and that the needs of the supervisee should be at the core of the clinical supervision. Clinical supervision ought to be regularly evaluated using the model as a guide to ensure the supervision experience continues to work successfully. ${ }^{36}$ The key to the supervisee experiencing successful clinical supervision is not that supervision consists of a fixed point of achievement that is built and then abandoned, but rather that supervisor and supervisee must be active in continually checking the four foundations of supervision and regularly redefining the clinical supervision.

Figure 1. The Allied Health Key Dimensions Model

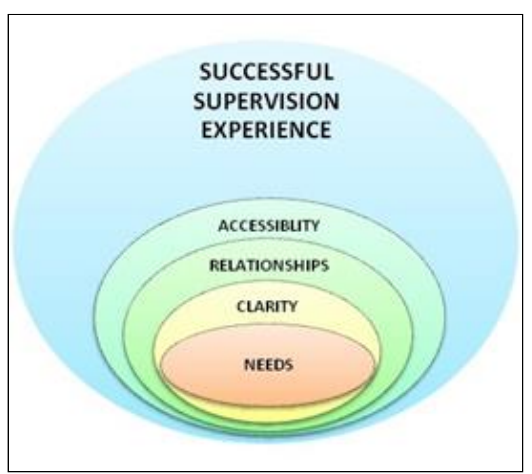

Most of the existing models for clinical supervision focus on implementation of supervision or the content of supervision in nursing and mental health contexts. For example models with a broad focus on implementation include Townend, who presented 
a model for psychosocial practitioners as a broad and complex framework. ${ }^{12}$ Models that focus on aspects of the workplace or organisation that affect implementation of clinical supervision include Gonge and Buus, who proposed a model that accounts for the relationship between clinical supervision and its anticipated benefits and the influence of workplace factors. ${ }^{34}$ Lynch and Happell and Driscoll also present models for supervision implementation in nursing with considerable attention to opposing workplace and organizational culture forces. ${ }^{36,37}$ Several models focus on the content of clinical supervision: Brunero and Lamont developed a supervision implementation model for nursing supervision session content; Ross presented a cognitive therapy supervision model specifically for mental health practitioners, and Page et al focused on a psychology case formulation model within the supervision session. ${ }^{14,17,38}$

The Allied Health Key Dimensions Model differs from these existing models in that it addresses both implementation and content of supervision and it is designed specifically for allied health staff and it can be used to enhance and evaluate individual, organizational, and group supervision. Thus, the model builds on knowledge and understanding of supervision and applies it in a broad way so that it has universal relevance and it also addresses a previously missed area of supervision: that of supervision in the allied health disciplines.

\section{Study Limitations}

There are several limitations to this study. Firstly, although there were 113 participants in this study, the percentage who participated of the total number of the allied health population was low. The anonymous nature of the survey did not allow profession identification; however, the overall distribution on supervisees to supervisors and were evenly spread with slightly less supervisee only participants. There was a higher participation amongst more experienced participants and this may relate to the availability of the internet-based survey for some allied health. Further studies should ensure that all participants have access to workplace based internet as this may have been a barrier to participation and have direct access to reminder emails to confirm widespread delivery. The range of experiences both chronologically and experientially combined with the in-depth nature of the study provided increased representation in this context. Secondly, the text collection method of using an internet-based survey may have limited the richness of the text collected. Face to face groups followed the survey to ensure a more in-depth source of text informed the researcher and confirmed text collected from the survey. Thirdly, only staff from one health service participated. A more heterogeneous sample that included staff from other services may have yielded different understandings of allied health supervision. The aim of the study was not to generalize to all health service settings, but to describe the current supervision experience in the settings described in a way that can contribute to transferability to other settings.

\section{CONCLUSION}

Drawing on a study of the experience of supervision from the perspectives of supervisors and supervisees, the authors propose that in allied health, successful clinical supervision is achieved by attending to four inter-related factors: a clinician's ready access to supervision; having a trusted and supportive supervisory relationship; being clear about what to expect from supervision and how it will be delivered; and receiving supervision that is focused on meeting the needs of the supervisee. The Allied Health Key Dimension's model builds on understandings of supervision that were revealed through understanding the supervision experiences of allied health staff and which were also identified in previous research. The model has broad applicability even though it was specifically developed for allied health staff. The authors suggest that the Allied Health Key Dimension Model may be of assistance in establishing and monitoring supervision at individual, team, and organizational levels.

\section{REFERENCES}

1. Fitzpatrick S. Allied Health Clinical Peer Supervision Policy. Illawarra Shoalhaven Local Health District: Illawarra Shoalhaven Local Health District; 2012:1-10.

2. Paulin V. Professional supervision in dietetics: A focus group study investigating New Zealand dietitians' understanding and experience of professional supervision and their perception of its value in dietetic practice. Nutrition \& Dietetics. 2010;67(2):106-11.

3. Hall T, Cox D. Clinical supervision: an appropriate term for physiotherapists? Learning in Health and Social Care. 2009;8(4):282-91.

4. Ostergren JA. The First Year of Professional Service in Speech-Language Pathology: Supervisory Role, Working Relationships, and Satisfaction With Supervision. Contemporary Issues in Communication Science and Disorders. Spring 2011;38:61-75.

5. O'Donoghue K, Tsui MS. Towards a professional supervision culture: The development of social work supervision in Aotearoa New Zealand. International Social Work. 2011;55(1):5-28.

6. Hunter EP, Blair SEE. Staff Supervision for Occupational Therapists. Br J Occup Ther. 1999;62(8):344-50. 
7. Herkt J, Hocking C. Participating in supervision: perceptions of occupational therapists in New Zealand. New Zealand Journal of Occupational Therapy. 2010;57(1):27-34.

8. Dawson M, Phillips B, Leggat SG. Effective clinical supervision for regional allied health professionals - the supervisee's perspective. Aust Health Rev. Feb 2012;36(1):92-7. [PMID:23498922]

9. Sweeney G, Webley P, Treacher A. Supervision in Occupational Therapy, Part 2: the supervisee's dilemma. Br J Occup Ther. 2001;64(8):380-6.

10. Kilminster SM, Jolly BC. Effective supervision in clinical practice settings: a literature review. Med Educ. 2000;34(10):827-40. [PMID:11012933]

11. Barriball L, While A, Munch U. An audit of clinical supervision in primary care. Br J Community Nurs. 2004;9(9):389-97. [PMID:15389151]

12. Townend M. Clinical supervision in cognitive behavioural psychotherapy: development of a model for mental health nursing through grounded theory. J Psychiatr Ment Health Nurs. 2008;15(4):328-39. [PMID:18387152]

13. White E, Winstanley J. A randomised controlled trial of clinical supervision: selected findings from a novel Australian attempt to establish the evidence base for causal relationships with quality of care and patient outcomes, as an informed contribution to mental health nursing practice development. J Res Nurs. 2010;15(2):151-67.

14. Ross M. Implementing clinical supervision in mental health practice. Mental Health Practice. 2013;17(2):34-9.

15. Ladany N, Mori Y, Mehr KE. Effective and Ineffective Supervision. The Counseling Psychologist. 2012 May;41(1):2847.

16. Grant A. Clinical supervision and organisational power: a qualitative study. Mental Health and Learning Disabilities Care. 2000 Aug; 31 (12):398-401.

17. Page AC, Stritzke WGK, McLean NJ. Toward science-informed supervision of clinical case formulation: a training model and supervision method. [corrected] [published erratum appears in Aust Psychol. 2008 Sep;43(3):213]. Aust Psychol. 2008;43(2):88-95.

18. Pearce P, Phillips B, Dawson M, Leggat SG. Content of clinical supervision sessions for nurses and allied health professionals: A systematic review. Clinical Governance: An International Journal. 2013;18(2):139-54.

19. Pickering M. Interpersonal communication in speech-language pathology supervisory conferences: A qualitative study. J Speech Hear Disord. 1984;49:189-95. [PMID:6371381]

20. LoBiondo-Wood G, Haber J. Nursing research: methods and critical appraisal for evidence-based practice. 8e. St. Louis, Missouri: Elsevier; 2014.

21. Yanow D. Interpretation and Method: Empirical Research Methods and the Interpretive Turn. Armonk, NY, USA: M.E. Sharpe, Inc; 2006.

22. Higgs J, Horsfall D, Grace S. Writing Qualitative Research on Practice. Rotterdam, The Netherlands: Sense Publishers; 2009.

23. Gadamer HG, Linge DE. Philosophical Hermeneutics. University of California Press; 2008.

24. Coyne IT. Sampling in qualitative research. Purposeful and theoretical sampling; merging or clear boundaries? J Adv Nurs. 1997;26(3):623-30. PMID:9378886

25. New South Wales Health. New South Wales Health Service Health Professionals (State) Award. 2007; http://www.health.nsw.gov.au/policies/ib/2007//B2007/ 059.html.

26. Hsieh H-F, Shannon SE. Three approaches to qualitative content analysis. Qual Health Res. 2005;15(9):1277. [PMID:16204405]

27. Van Manen M. Researching Lived Experience: Human Science for an Action Sensitive Pedagogy, 2e. London, Ont.: Althouse Press; 1997.

28. Guba EG, Lincoln YS. Fourth generation evaluation. Newbury Park, California: Sage Publications; 1989.

29. Graneheim UH, Lundman B. Qualitative content analysis in nursing research: concepts, procedures and measures to achieve trustworthiness. Nurse Educ Today. 2004;24(2):105-12. [PMID:14769454]

30. Elo S, Kyngäs $H$. The qualitative content analysis process. J Adv Nurs. 2008;62(1):107-15. [PMID:18352969]

31. Smith J. Hermeneutics, human sciences and health: linking theory and practice. International Journal of Qualitative Studies on Health and Well-Being. 2007;2(1):3-11.

32. Dowling M. From Husserl to van Manen. A review of different phenomenological approaches. Int J Nurs Stud. 2007;44(1):131-42. [PMID:16412442]

33. Creswell JW. Qualitative Inquiry \& Research Design: Choosing Among Five Approaches, 3e. Thousand Oaks, California: Sage Publications, Inc; 2013.

34. Gonge H, Buus N. Model for investigating the benefits of clinical supervision in psychiatric nursing: a survey study. Int J Ment Health Nurs. Apr 2011;20(2):102-11. PMID:21371225

35. Grant J, Schofield MJ, Crawford S. Managing Difficulties in Supervision: Supervisors' Perspectives. Journal of Counseling Psychology. 2012;59(4):528-41. doi: 10.1037/a0030000 PMID:23088684 
36. Lynch B, Happell, B. Implementation of clinical supervision in action: Part 3: The development of a model. Int J Ment Health Nurs. 2008;17:73-82. PMID:18211406

37. Driscoll J. Practicing Clinical Supervision; A Reflective Approach. London UK: Harcourt Publishers; 2000.

38. Brunero S, Lamont $S$. The process, logistics and challenges of implementing clinical supervision in a generalist tertiary referral hospital. Scand J Caring Sci. Mar 2012;26(1):186-93. PMID:21883342. [PMID:18352969] 